\title{
HIV/AIDS and Economic Growth: Empirical Evidence from Sub-Saharan Africa
}

\author{
Danjuma Maijama'a, ${ }^{1,2}$, Shamzaeffa $\operatorname{Samsudin}^{1} \&$ Shazida jan Mohd Khan ${ }^{1}$ \\ ${ }^{1}$ School of Economics, Finance and Banking, College of Business, University Utara Malaysia, \\ 06010 UUM Sintok, Kedah, Malaysia \\ ${ }^{2}$ School of General Studies, Abubakar Tatari Ali Polytechnic, PMB 0094 Wuntin Dada \\ Bauchi, Nigeria \\ *Correspondence: School of Economics, Finance and Banking, College of Business, \\ University Utara Malaysia, 06010 UUM Sintok, Kedah, Malaysia. E-mail: \\ danjumarabiuu@gmail.com
}

Received: October 14, 2015 Accepted: November 16, 2015 Published: December 7, 2015

doi:10.5296/rae.v7i4.8426 URL: http://dx.doi.org/10.5296/rae.v7i4.8426

\begin{abstract}
This study investigates the effects of the HIV and AIDS epidemic on economic growth in 42 sub-Saharan African countries using data spanning from 1990-2013. Unlike previous studies, we use a longer data horizon and take the time lag effect of the epidemic's incubation period that is, after it might have developed to AIDS into consideration in our estimations. We estimated an empirical growth equation within an augmented Solow model and applied the dynamic system GMM estimator. The results suggest that current HIV prevalence rate associated with rising morbidity, has a negative effect on GDP per capita growth, conversely AIDS - associated with higher mortality in addition to morbidity, increases per capita GDP growth.
\end{abstract}

Keywords: HIV/AIDS, Economic growth, GDP per capita, sub-Saharan Africa

JEL Classification: H51, H52, H53, H75, O15 


\section{Introduction}

Health is not only central to individual well-being, but is also indispensable in the process of growth and development. Health as a form of human capital is among the basic inputs in the aggregate production function. Therefore, it is a fundamental component of economic growth of every society. Essentially, enhancing the health status of the vast majority of the population is not only an end in itself, but also a means to attain other ends such as poverty reduction, better standards of living and consequently economic progress (Todaro \& Smith, 2005). However, morbidity and mortality associated with HIV/AIDS could, through depleting critical sectors of the work-force, retard economic performance of societies and hence obstruct development efforts (Mayer, 2001).

Since its appearance over three decades ago, HIV/AIDS has become pandemic on a global scale as well as remain the most devastating disease humankind has ever faced. Worldwide, it is the fourth killer disease; however, it causes more death than any other disease in sub-Saharan Africa (SSA) (Joint United Nations Programme on HIV/AIDS [UNAIDS] \& World Health Organization [WHO], 2001; UNAIDS, 2007; WHO, 2008). Now the epidemic is not only regarded as on health issue, but also seen as a substantial threat to economic growth and development. HIV infects people at their most productive age (15-49 years) (UNAIDS \& WHO, 2001; WHO, 1995), imposing a serious burden on families, communities and ultimately economies (Kambou, Devarajan \& Over, 1992; McDonald \& Roberts, 2006). The number of individuals living with HIV/AIDS worldwide has drastically increased over the past three decades, with the prevalence rate estimated to rise from 18.0 million persons in 1994 to 33.0 million in 2009 (UNAIDS \& WHO, 2009; 2010). Recent epidemiological data estimates that from the time the epidemic was realized about 75 million persons worldwide have become HIV positive and 36 to 42 million people had died due to illnesses associated with HIV/AIDS (UNAIDS, 2013).

In sub-Saharan Africa, the HIV/AIDS epidemic is widely spread and continues to infect people. The rate of infection has cut across all sexes, ethnic groups, and religion, hence it spared no one. The epidemic's devastating effects are felt both by those infected as well as by those indirectly affected (UNAIDS \& WHO, 2009). In the region, the prevalence rate among the highly vulnerable age cohort (15-49 years) increased from 20.9 million (5.8\%) in 2001 to over 28.0 million people in 2013 (UNAIDS, 2014). Specifically, in 2007 the estimated prevalence rate was greater than 28 percent in the heavily infected South African countries like Lesotho, Botswana, Namibia, South Africa, and Swaziland among others. In the East African countries, the highly infected countries include: Mozambique, Zambia, and Zimbabwe among others (UNAIDS, 2008). While sub-Saharan Africa contains just about 12 percent of global population (World Bank, 2011), it accounts for the highest number $(69 \%)$ of people living with HIV/AIDS and 3/4 (75\%) of all global deaths due to AIDS related illnesses (UNAIDS, 2012; 2013). The size of the epidemic in many sub-Saharan African countries is capable of inducing adverse major changes in economic and social relationships with consequential implications on macroeconomic performance indicators such as per capita income growth and/or GDP growth. In most cases, whenever the epidemic strikes family living standards become harsh as infected adults are less or unable to work to sustain the 
family. Gradually, children's education is terminated in order to maintain sick parent(s) or to be forced into the labour market to support the family (McDonald \& Roberts, 2006).

The association between HIV/AIDS and macroeconomic indicators is complex owing to the several channels of transmission mechanisms (Haacker, 2011). There was consensus that the HIV epidemic could reduce aggregate labour productivity, which in turn will reduce output, investment, income, and subsequently lower the growth of national economies (Dixon, McDonald \& Roberts, 2002). However, the effect of the epidemic on per capita income seems to be indeterminate due to two opposing factors. On the one hand, a reduction in the labour force due to AIDS related mortality could increase per capita income while on the other hand; reduction in domestic savings due to HIV/AIDS spending will reduce capital formation and investment which in turn will lead to a decline in per capita income, and hence declining economic growth (Bonnel, 2000; Cuddington, 1993).

The realization among economists and policy makers that HIV/AIDS is not only a health issue but also a serious threat to macroeconomic performance has led several studies to examine the consequences of the epidemic on economic growth. Initial quantitative investigations of the macroeconomic effects of the HIV/AIDS were compromised by lack of appropriate and adequate data. Consequently, more or less simulations and/or calibrated growth models were applied to estimate the effects of the epidemic on the macroeconomy (McDonald \& Roberts, 2006). Some of the early empirical studies like (Ainsworth \& Over, 1994; Cuddington \& Hancock, 1994) and recently (Murtin \& Marzo, 2013) have shown that the economic consequences were mild, hence of no serious concern. Moreover, Bloom and Mahal (1997) found that HIV/AIDS has statistically insignificant effect on per capita income growth and conclude that there is more flash than substance to the argument that the epidemic obstructs economic growth. Nevertheless, one is inclined to doubt the robustness of Bloom and Mahal results, because the estimates were derived from 1980 to 1992 data, a period when the HIV/AIDS prevalence was very low with limited impact on morbidity and mortality. Another study even established a positive link between HIV/AIDS and per capita GDP growth, where estimates show that the latter will increase by 1 percent due to the former, in South Africa (Young, 2005).

However, other quantitative investigations reached opposite conclusions. Their estimates show that the macroeconomic effects of the HIV/AIDS were something of serious concern (Arndt \& Lewis, 2000; Bonnel, 2000; Lovasz \& Schipp, 2009; McDonald and Roberts 2006; World Bank, 2000; 2001). Nevertheless, Dixon, McDonald and Roberts (2001) argue that in the presence of relatively high HIV/AIDS prevalence rate, the epidemic's effect on the macroeconomy is equivocal and unclear. Obviously, the empirical investigations of the macroeconomic effects of the HIV/AIDS epidemic produced mixed results. This could not be unconnected with the lack of appropriate data. Also, it could be due to the use of simulations and/or calibrated growth models and their assumptions that are often difficult to justify, in deriving the quantitative estimates. In addition, although HIV have incubation period of about 7-10 years, between infection to development of AIDS (Kanki et al., 1999), to our understanding, previous studies have failed to take the time lag effect of such period into consideration in their estimated equation. This might have affected the robustness of their 
results. Therefore, in consideration of the time lag, our analysis will essentially examine the effect of HIV, which is associated with rising morbidity on economic growth. The effect of AIDS will also be examined, being associated with rising mortality in addition to morbidity.

The HIV/AIDS epidemic is now in its fourth decade. There have been considerable improvements in scientifically designed seroprevalence surveys in several countries which produced substantial and appropriate data on the epidemic. Unlike previous studies, this paper investigates the effects of HIV and AIDS on per capita GDP growth, using an appropriate and longer data horizon. It also takes the epidemic's time lag effect that is, after it might have developed to AIDS into consideration while controlling for other factors that possibly influence growth. We also examine the sensitivity of the results using two alternative sub samples. Among the measures or indicators of economic growth, economists basically use real per capita GDP growth (Levine \& Zervos, 1998). Our empirical analyses uses panel data and we applied the dynamic system Generalized Method of Moments (GMM) estimator proposed by Blundell and Bond (1998) in estimating the equation. The GMM estimator takes care of time in-variant country characteristics, that is, unobserved specific effects which may be correlated with the explanatory variables, mitigates the endogeneity of the regressors, avoids dynamic panel bias and accommodates unbalanced and short panels. Our model has two key features: (i) current HIV prevalence rate; and (ii) lagged HIV prevalence rate.

This study contributes to the existing literature on the relationship between HIV/AIDS and economic growth by estimating the effect using appropriate and longer cross-country data, as well as taking the time lag effect of the epidemic's incubation period into consideration. Thus, the study avoids the traps of simulations and/or calibrated growth models with their assumptions that are difficult to justify. While the next section deals with the methodology, the empirical results and discussion is presented in section 3 , and section 4 concludes the paper.

\section{Methodology}

We examine whether HIV/AIDS epidemic has a negative effect on per capita real GDP growth in sub-Saharan Africa using panel data analysis within an augmented Solow growth model. The significance of human capital in the growth process has long been stressed to such an extent that one expects ignoring it will result in wrong conclusions (Kendrick, 1976). Mankiw, Romer and Weil (1992) augmented the Solow growth model with human capital in the form of education to offset any misspecification bias that will ensue if both physical and human capital exist but human capital is omitted in the estimated equation. However, it has been argued that human capital is multidimensional and consists of more than education, thus any misspecification bias will only be adequately accounted for if other dimensions of human capital are included in the estimation. McDonald and Roberts (2006) extended the Mankiw et al. augmented Solow model to incorporate health capital as a component of human capital in addition to educational capital. 


\subsection{The Augmented Solow Model}

Consider that the aggregate production function for the augmented Solow model is as a Cobb-Douglas function which assumes constant returns to scale and labour augmenting technological progress, and is express in the following form:

$$
Y_{i t}=\left(A_{i t} L_{i t}\right)^{1-\alpha-\beta-\lambda} K_{i t}^{\alpha} E_{i t}{ }^{\beta} H_{i t}{ }^{\lambda}
$$

where $Y$ is output, $A$ the level of technology, $L$ labour, $K$ physical capital, $E$ educational capital, $H$ health capital, $\alpha, \beta$, and $\lambda$ are the output elasticities with respect to the various capital inputs. The subscripts denote country $i=1,2 \ldots \mathrm{N}$, and time $t=1,2 \ldots \mathrm{T}$. Equation 1 can be condensed as

$$
y_{i t}=k_{i t}^{\alpha} e_{i t}^{\beta} h_{i t}^{\lambda}
$$

where $\mathrm{y}_{i t}$ is output per unit of effective labour $\left(\mathrm{A}_{i t} \mathrm{~L}_{i t}\right)$ in country $i$ at time $t$, and $\mathrm{k}_{i t}, \mathrm{~h}_{i t}$ and $\mathrm{e}_{i t}$ are the respective quantities of capitals per effective worker.

Based on Mankiw et al. (1992), McDonald and Roberts (2006) derived the steady - state output per capita $\left(y_{i t}^{*}\right)$ in terms of the parameters of the production function with the assumption that labour grows at country specific rates $n_{i}$, technology grows at period specific rates $g_{t}$, and physical, educational and health capital stocks depreciate at the same rate $\delta_{\mathrm{t}}$ and there are country specific initial states of technology $A_{i 0}$, then

$$
\begin{gathered}
k_{i t}=1^{K_{i, t-1}}+(1-\delta) k_{i, t-1} \\
E_{i t}=1^{E}{ }_{i, t-1}+(1-\delta) E_{i, t-1} \\
H_{i t}=1^{H}{ }_{i, t-1}+(1-\delta) H_{i, t-1}
\end{gathered}
$$

where savings are divided among physical, education and health capital accumulation, and treating education and health capital as investment activity, so that

$$
s_{i t}=s_{i t}{ }^{K}+s_{i t}{ }^{E}+s_{i t}{ }^{H}=\frac{S_{i t}}{Y_{i t}}=\frac{I_{i t}}{Y_{i t}}=\frac{I_{i t}{ }^{K}+I_{i t}{ }^{E}+I_{i t}{ }^{H}}{Y_{i t}}
$$

then, the rates of physical, educational and health capital growth per unit of effective labour become

$$
\begin{gathered}
\hat{k}_{i t}=s_{i}{ }^{K} \hat{y}_{i t}-\left(n_{i}+g_{t}+\delta_{t}\right) \hat{k}_{i t} \\
\hat{e}_{i t}=s_{i}{ }^{E} \hat{y}_{i t}-\left(n_{i}+g_{t}+\delta_{t}\right) \hat{e}_{i t} \\
\hat{h}_{i t}=s_{i}{ }^{H} \hat{y}_{i t}-\left(n_{i}+g_{t}+\delta_{t}\right) \hat{h}_{i t}
\end{gathered}
$$


where $s_{i}{ }^{K}, s_{i}{ }^{E}$ and $s_{i}{ }^{H}$ are the portion of income devoted to investment in physical, educational and health capitals, respectively, and $\delta$ represents the common depreciation rate, assumed constant over time.

and incorporating the three capitals - physical, educational and health the augmented steady state output per capita becomes

$$
\begin{aligned}
\ln {y_{i t}}^{*}=\ln A_{i(0)}+ & g_{t} t-\frac{\alpha+\beta+\lambda}{(1-\alpha-\beta-\lambda)} \ln \left(n_{i}+g_{t}+\delta\right)+\frac{\alpha}{(1-\alpha-\beta-\lambda)} \ln s_{i}{ }^{K} \\
& +\frac{\beta}{(1-\alpha-\beta-\lambda)} \ln s_{i}{ }^{E}+\frac{\lambda}{(1-\alpha-\beta-\lambda)} \ln s_{i}{ }^{H}
\end{aligned}
$$

linearising (6) around the steady state level of income per unit of effective worker, $\mathrm{y}_{\mathrm{it}}$, following Mankiw et al., gives

$$
\begin{aligned}
\ln y_{i t^{*}}-\ln y_{i 0^{*}}= & \left(1-\exp ^{\lambda t}\right) \ln A_{i 0}+g_{t} t-\frac{\left(1-\exp ^{\lambda t}\right) \alpha}{(1-\alpha)} \ln \left(n_{i}+g_{t}+\delta\right)+\frac{\left(1-\exp ^{\lambda t}\right) \alpha}{(1-\alpha)} \ln s_{i}{ }^{K} \\
& +\frac{\left(1-\exp ^{\lambda t}\right) \beta}{(1-\alpha)} \ln {s_{i}}^{E}+\frac{\left(1-\exp ^{\lambda t}\right) \psi}{(1-\alpha)} \ln h_{i t^{*}}-\left(1-\exp ^{\lambda t}\right) \ln y_{i 0^{*}}
\end{aligned}
$$

An empirical advantage of the Mankiw et al. method is that it allows for the mixing of stock and saving/investment data for the capital components of the estimating equation.

Solving (7) for $\operatorname{lny}_{i t}$ and applying standard panel data notation, yields the general specification of the econometric growth model which we estimate in this paper.

$$
\gamma_{i t}^{*}=\theta \gamma_{i 0^{*}}+\sum_{j=1}^{n} \phi_{j} x_{i t}^{j}+\mu_{t}+v_{i}+\varepsilon_{i t}
$$

where $\gamma_{i t}^{*}$ is per capita GDP growth rate, $\gamma_{i 0^{*}}$ is the initial level of per capita GDP of country $i, x_{i t}^{j}$ are vectors of variables that may influence the growth rate, $\phi_{j}$ are vector of parameters, $\mu_{t}$ is a time specific effect, $v_{i}$ are the unobserved individual specific time invariant effects and $\varepsilon_{i t}$ is the stochastic term.

Equation (8) introduces the HIV prevalence rate and the AIDS into the augmented Solow model that relates GDP per capita growth to a number of variables. The relevance of this relationship has been established in the empirical literature on growth (e.g. Barro, Sala-i-Martin, Blanchard \& Hall, 1991; Forgel, 1994; Knowles \& Owen, 1995). The vector of control variables includes the initial level of GDP per capita, population growth, gross domestic savings, gross capital formation, education as well as trade openness. 


\subsection{Data}

The main source of data for the analysis is the World Bank (2014). The World Bank contains the most current and accurate national, regional and global development indicators, compiled from international sources that are officially recognized by the Bank. Due to lack of adequate data on the proxy variables for all the sub-Saharan African countries, the study covers only 42 countries. In addition to the main sample, there are two alternative sub-samples; 18-country Eastern and Southern Africa and 24-country Rest of sub-saharan Africa. The data are annual spanning from 1990-2013. We average the data over non-overlapping 2-year time intervals, for 12 periods. Being HIV prevalence rate as cumulative, 6 years is enough for HIV to develop to AIDS. Consequently, the introduction of the AIDS requires lagging of the HIV prevalence rate, which reduced the initial 12 periods to 6 due to missing of some observations. This explains that HIV prevalence rate in 1990 is transformed to AIDS in 1996, and so forth. Time dummies are included in the regressions, because they ease the effects of fluctuations in the GDP per capita growth as well as increase the likelihood that the assumptions of no correlation across individuals in the idiosyncratic disturbance will be valid (Roodman, 2009).

The dependent variable is GDP per capita growth $(g d p)$ where $g d p=\ln (1+G D P)^{1}$, and GDP were calculated using real GDP in constant US dollar prices for the year 2005 and the number of population reported in World Development Indicators (World Bank, 2014). HIV prevalence describes the total number of persons living with HIV/AIDS at a time, regardless of when they become infected (UNAIDS, 2005). Though the operationalization of health capital at macro level is yet to be adequately explained by any economic theory (Lovasz \& Schipp, 2009), some studies exist which measure the effect of diseases at this level (Murray \& Lopez, 1996). Considering the primary aim of estimating the effect of HIV/AIDS epidemic on GDP per capita growth, we specify health capital in a country via the HIV/AIDS prevalence rate, because it describes the level of health status of societies (McDonald \& Roberts, 2006) which is part of health capital accumulation. We have two measures of HIV/AIDS: (i) current values of the HIV prevalence rate; to show the instantaneous effect and (ii) lag values of the HIV prevalence rate (hereafter AIDS) ${ }^{2}$ to show the effect after the HIV converts to AIDS. We use the HIV prevalence rate for adults aged (15-49) years reported in World Development Indicators (World Bank, 2014), which is the most widely employed in empirical studies, to capture the severity of the HIV/AIDS epidemic.

The control variables were included following the literature on economic growth. Physical capital of the economies was operationalised by gross capital formation as a share of GDP, while saving which is GDP less final consumption expenditure is measured by gross domestic savings as a percentage of GDP ${ }^{3}$. Trade openness is also measured by trade as a percentage of GDP. Population growth ${ }^{4}$ serves as a proxy to population, while in proxy to education we use secondary school enrolment rate ( $\%$ gross). All are from World Development Indicators (World Bank, 2014). As a robustness check, we have re-estimated the model by substituting some of the control variables with comparable proxies to test the stability of coefficients of the key explanatory variables.

Table 1 provides some descriptive statistics on the basic features of the data, and the full list 
of the sampled countries is shown in appendix 1. As indicated in the Table, the minimum value of the HIV prevalence rate within all the samples is the same $(0.10 \%)$, but the maximum value differs. While the maximum value in the full sample corresponds to that of Eastern and Southern Africa, 28.40\%, for the Rest of sub-Saharan Africa is $8.95 \%$.

Table 1. Descriptive Statistics

\begin{tabular}{|c|c|c|c|c|}
\hline VARIABLE & Mean & Std. Dev & Min & Max \\
\hline \multicolumn{5}{|l|}{ Full Sample } \\
\hline GDP per capita growth & 1.77 & 7.17 & -33.06 & 101.67 \\
\hline HIV prevalence rate & 5.45 & 6.68 & 0.10 & 28.40 \\
\hline Population growth (annual gr.) & 2.52 & 1.12 & -6.97 & 9.68 \\
\hline Gross capital formation/GDP (\%) & 23.49 & 18.30 & 2.58 & 186.73 \\
\hline Gross domestic saving/GDP (\%) & 11.29 & 21.31 & -74.73 & 119.11 \\
\hline Trade/GDP $(\%)$ & 78.24 & 51.15 & 13.08 & 471.93 \\
\hline Sch. enrolment secondary (\% gross) & 32.97 & 20.73 & 1.22 & 106.33 \\
\hline Total population & 16200000 & 23700000 & 355801 & 171000000 \\
\hline Secondary edu. general pupil & 655394 & 1139535 & 749 & 7500000 \\
\hline \multicolumn{5}{|l|}{ Eastern and Southern Africa } \\
\hline GDP per capita growth & 1.79 & 3.30 & -13.25 & 9.66 \\
\hline HIV prevalence rate & 9.67 & 8.28 & 0.10 & 28.40 \\
\hline Population growth (annual gr.) & 2.27 & 1.34 & -6.97 & 9.68 \\
\hline Gross capital formation/GDP (\%) & 21.86 & 9.47 & 3.02 & 68.70 \\
\hline Gross domestic saving/GDP (\%) & 7.49 & 16.97 & -62.30 & 53.97 \\
\hline Trade/GDP $(\%)$ & 71.83 & 40.26 & 13.08 & 204.67 \\
\hline Sch. enrolment secondary (\% gross) & 37.82 & 24.43 & 5.30 & 106.33 \\
\hline Total population & 18500000 & 18600000 & 874988 & 92900000 \\
\hline Secondary edu. general pupil & 788003 & 1081455 & 29898 & 4700000 \\
\hline \multicolumn{5}{|l|}{ Rest of sub-Saharan Africa } \\
\hline GDP per capita growth & 1.75 & 9.06 & -33.06 & 101.67 \\
\hline HIV prevalence rate & 2.29 & 1.82 & 0.10 & 8.95 \\
\hline Population growth (annual gr.) & 2.70 & 0.89 & -1.69 & 7.38 \\
\hline Gross capital formation/GDP (\%) & 24.71 & 22.71 & 2.58 & 186.73 \\
\hline Gross domestic saving/GDP (\%) & 14.14 & 23.69 & -74.73 & 119.11 \\
\hline Trade/GDP $(\%)$ & 83.05 & 57.59 & 26.03 & 471.93 \\
\hline Sch. enrolment secondary (\% gross) & 29.34 & 16.59 & 1.22 & 92.74 \\
\hline Total population & 14500000 & 26800000 & 355801 & 171000000 \\
\hline Secondary edu. general pupil & 555938 & 1173259 & 749 & 7500000 \\
\hline
\end{tabular}


Generally, HIV prevalence rates are higher in Eastern and Southern Africa with a mean prevalence rate of $9.67 \%$ compared to $5.45 \%$ and $2.29 \%$ in the full sample and Rest of sub-Saharan Africa, respectively.

\subsection{Estimation Procedure}

In estimating the regression equation, we employ the GMM estimator which is one of the techniques use in dynamic panel data models (Baltagi, 2005). Dynamic panel data models contain the lagged dependent variable among the regressors which correlates with the error term. This presents endogeneity problem and renders standard estimators - pooled OLS, fixed effects and random effects inconsistent and bias. The GMM estimator proposed by Arellano and Bond (1991) deals with the endogeneity issues and provides consistent estimates for such models. This estimator, commonly referred to as the 'difference' GMM, first differences the regression equation and then uses the lagged values of the endogenous variables as instruments. However, Arellano and Bover (1995) and Blundell and Bond (1998), argued that when the time series are persistence or close to random walk processes, the lagged values of the variables are weakly correlated with the endogenous variable hence, are weak instruments for the regression in differences. Thus, Blundell and Bond proposed a more efficient estimator - the system GMM, which addresses the weak instruments problems by using additional moment conditions. That is, combining the moment conditions for the differenced model with those for the levels model. Hence, the more efficient, less biased system GMM is used in the estimation.

Some potential issues of the system GMM need to be pointed out: validity of the instruments, and the assumption that there is no second order autocorrelation in the errors. To deal with these potential problems, we use Sargan test of overidentifying restrictions and Arellano and Bond test for autocorrelation in the regression. Failing to reject the null hypotheses with respect to the former means instruments are valid that is, not correlated with the error term while with regards to the latter it indicates absence of second order autocorrelation in first-differenced errors. Another important issue is that, if the number of the instruments is large relative to the sample size, the Sargan and the autocorrelation tests may lose their predictive power. Specifically, the underlying assumptions of the two procedures are likely to be violated if the instrument ratio is less than 1 (Roodman, 2009). This problem is easily addressed by constraining the instruments through limiting the number of lags to be included in the estimation (Roodman, 2009). We use two-step GMM estimator which is more efficient and robust to heteroskedasticity (Asiedu, Jin \& Kanyama, 2011).

In the estimation, we first start with the full sample regression where we examine whether HIV/AIDS has a negative effect on GDP per capita growth after controlling for other factors that might influence growth, before examining the sensitivity of the results within the two alternative sub-samples. In step two, in all the samples, we check robustness of the results to substitution of some control variables. 


\section{Results and Discussion}

The empirical results for the full sample and the two alternative sub-samples are reported in Table 2. The coefficient of the lagged per capita income is positive and significant, suggesting that convergence is taking place. This is in line with McDonald and Roberts (2006). The coefficients on education and gross capital formation have the predicted signs and are significant. Conversely, the parameters' estimate for the population and saving returns with unexpected signs yet, are also significant. There is no evidence to support the idea that trade openness has a significant influence on GDP per capita growth. The main focus of the paper is with respect to the coefficients of the current HIV prevalence rate and AIDS which proxy health capital. The coefficient on current HIV prevalence rate (lnhiv) is negative as expected and significant at $1 \%$ level. AIDS ( $\left.\operatorname{lnAIDSL}_{6}\right)$ is also significant and returns with positive sign. The specification and the autocorrelation tests are sound. In both the samples, the p-values for the Sargan test and the autocorrelation test shows validity of the instruments and absence of second order autocorrelation in first-differenced errors. This means that the model and overidentifying conditions are correctly specified. Thus, the tests support the validity and reliability of the system GMM estimator in the analysis.

Within the full sample, the positive effect of education and investment in physical capital implies that they have been beneficial to economic growth in sub-Saharan Africa within the period. Remarkably, the results show that secondary school enrolment rate in the region's economies has a higher impact on growth compared to gross capital formation. With respect to saving, being negative and significant constitutes a leakage, suggesting that it depressed the performance of the economies.

Current HIV prevalence is found to have negatively affected GDP per capita, suggesting that it reduces economic growth in the region. The current HIV prevalence is principally associated with rising morbidity than mortality which, due to treatment and maintenance led to increase in private and public health expenditure and consequently decline in domestic saving. The fall in domestic saving reduces capital formation and investment which in turn lead to decline in per capita income, hence declining economic growth. Thus, this result gives strong support to the claim that HIV epidemic reduces the growth of national economies, and is in line with the findings of (Cuddington, 1993; Lovasz \& Schipp, 2009; McDonald \& Roberts, 2006; World Bank, 2000).

Consequently, after the disease might have developed to AIDS, it is found to have a positive and significant effect on GDP per capita, which is in consonance with (Dixon et al., 2001; Young, 2005). In addition to morbidity, AIDS is associated with rising mortality, which has significantly increased the number of deaths in sub-Saharan Africa (UNAIDS \& WHO, 2009). This implies that, as death increases due to AIDS; population growth will decline, resulting in lower populations at certain periods leading to higher GDP per capita. Especially, if the population declined is not offset by proportional decline in GDP. Nevertheless, the positive effect of AIDS on per capita GDP should not be construed as beneficial to economic growth in the region, as it was due to a decrease in population rather than growth augmenting policies or economic activities. 
Table 2. The Effect of HIV/AIDS on Per Capita GDP Growth Rate: Main Regression

\begin{tabular}{|c|c|c|c|}
\hline & $\begin{array}{l}\text { Sub-Saharan } \\
\text { Africa }\end{array}$ & $\begin{array}{l}\text { Rest of sub-Saharan } \\
\text { Africa }\end{array}$ & $\begin{array}{l}\text { Eastern \& Southern } \\
\text { Africa }\end{array}$ \\
\hline \multirow[t]{2}{*}{$\operatorname{lng} d p_{i t-1}$} & $0.152^{* * *}$ & $0.146^{*}$ & 0.014 \\
\hline & $(0.031)$ & $(0.085)$ & $(0.066)$ \\
\hline \multirow[t]{2}{*}{ lnhiv } & $-0.689 * * *$ & $-0.133 * * *$ & -0.034 \\
\hline & $(0.021)$ & $(0.043)$ & $(0.036)$ \\
\hline \multirow[t]{2}{*}{$\ln A I D S L_{6}$} & $0.031 * * *$ & 0.025 & $0.041 * * *$ \\
\hline & $(0.007)$ & $(0.021)$ & $(0.012)$ \\
\hline \multirow[t]{2}{*}{$\operatorname{lnedu}$} & $0.065 * *$ & 0.055 & -0.024 \\
\hline & $(0.032)$ & $(0.097)$ & $(0.054)$ \\
\hline \multirow[t]{2}{*}{ lnpop } & $0.249 * *$ & 0.113 & 0.305 \\
\hline & $(0.100)$ & $(0.121)$ & $(0.378)$ \\
\hline \multirow[t]{2}{*}{$\operatorname{lng} d s$} & $-0.021 * * *$ & $-0.020 * *$ & 0.159 \\
\hline & $(0.006)$ & $(0.008)$ & $(0.109)$ \\
\hline \multirow[t]{2}{*}{$\operatorname{lng} c f$} & $0.053 * * *$ & $0.054 * * *$ & 0.005 \\
\hline & $(0.014)$ & $(0.014)$ & $(0.019)$ \\
\hline \multirow[t]{2}{*}{ lnopn } & -0.012 & -0.003 & $0.139 * * *$ \\
\hline & $(0.028)$ & $(0.038)$ & $(0.039)$ \\
\hline Observations & 252 & 144 & 108 \\
\hline Countries & 42 & 24 & 18 \\
\hline Instruments & 30 & 20 & 20 \\
\hline Sargan test (p-value) & 0.193 & 0.519 & 0.447 \\
\hline AR (2) test (p-value) & 0.666 & 0.511 & 0.393 \\
\hline
\end{tabular}

Notes: Dependent variable $\left(\operatorname{lng} d p_{i t-1}\right)$ : GDP per capita growth; lnhiv: HIV prevalence rate; $\ln A I D S L_{6}$ : AIDS; lnedu: secondary school enrolment ratio; lnpop: population growth; lngcf: capital formation; lngds: gross domestic savings; lnopn: openness; standard errors in parentheses; ***, ** and * denotes significance at the 1, 5 and $10 \%$ levels, respectively; all time dummies are allowed for but not reported to save space.

One might argue that, the death rate could be nullified by birth rate. However, Bos and Bulatao (1992) maintain that; the effect of higher mortality rates will offset any change in birth rates, resulting in the decline in population growth rates. They further indicate that the birth rate could be affected by the AIDS epidemic, because fertility rate will change as women alter their childbearing behaviour due to economic and non economic considerations in response to increased AIDS prevalence. Also, higher AIDS prevalence could change the number of women within the childbearing age cohort, thereby affecting the overall birth rate.

As earlier mentioned, the sample is divided into two sub-samples to examine whether differences exist in the two samples. The Eastern and Southern Africa sub-sample has higher average HIV prevalence than the Rest of sub-Saharan Africa sample. The coefficients on gross capital formation and saving in the Rest of sub-Saharan Africa sample are similar in magnitude and signs to those obtained in the full sample. In the Eastern and Southern Africa sub-sample, these coefficients even though have the predicted signs, show no significance. However, trade openness is significant, unlike in the full sample and the Rest of sub-Saharan 
Africa sub-sample. In both the two sub-samples the parameter estimates for education are not significant, although correctly signed in the Rest of sub-Saharan Africa sample.

The results support the evidence that current HIV prevalence rate in the Rest of sub-Saharan Africa sample, is significant and depressed economic growth as in the full sample. AIDS is, however, not significant, although it has the positive sign. The insignificant effect of AIDS in the former sample might have resulted due to the low HIV prevalence rate in the sample which tend to mitigate the development and spread of the AIDS epidemic, and thus nullifies its potential consequences. Similar to what was obtained in the full sample; AIDS, in the highly infected Eastern and Southern Africa sub-sample has significant positive effect on the growth of GDP per capita. As earlier mentioned, this could be due to the large number of deaths; AIDS related and otherwise which characterized highly infected societies, and ultimately, reduces the population. Conversely, and in line with (Lovasz \& Schipp, 2009), current HIV prevalence was not significant, even though it returns with the expected sign. The failure of current HIV prevalence to influence GDP per capita in the Eastern and Southern Africa sub-sample could be explained by the decline in the rate of new HIV infection in the entirety sub-Saharan Africa as pointed out by UNAIDS (2013).

As a robustness check, we re-estimated the model after substituting secondary school enrolment ratio, population growth and gross domestic saving with comparable proxies, in order to test the stability of the coefficient estimates of the variables of interest. As shown in Table 3, the results for the key explanatory variables are robust: lnhiv and $\ln A I D S L_{6}$, in the full sample as well as the two alternative sub-samples maintained their signs and are equally significant. In addition, across the specifications, the magnitudes of these coefficients are fairly stable. However, of the substitute's variables, we find that the secondary education general pupil and the total population are not significant, hence do not affect economic growth in the analysis. On the other hand, the coefficient of gross saving in the full sample and the Rest of sub-Saharan Africa is significant but wrongly signed, suggesting that it has negative influence on the performance of the economies. Conversely, in the Eastern and Southern Africa sub-sample, the gross saving has the expected sign, yet not significant. 
Table 3. The Effect of HIV/AIDS on per Capita GDP Growth Rate: Robustness Regression

\begin{tabular}{|c|c|c|c|}
\hline & $\begin{array}{l}\text { Sub-Saharan } \\
\text { Africa }\end{array}$ & $\begin{array}{l}\text { Rest of sub-Saharan } \\
\text { Africa }\end{array}$ & $\begin{array}{l}\text { Eastern \& Southern } \\
\text { Africa }\end{array}$ \\
\hline$g \operatorname{lnpgr} r_{i t-1}$ & $\begin{array}{l}0.121 * * * \\
(0.028)\end{array}$ & $\begin{array}{l}0.149 * * * \\
(0.051)\end{array}$ & $\begin{array}{l}0.014 \\
(0.066)\end{array}$ \\
\hline $\operatorname{lnhiv}$ & $\begin{array}{l}-0.069^{* * *} \\
(0.016)\end{array}$ & $\begin{array}{l}-0.091 * \\
(0.050)\end{array}$ & $\begin{array}{l}-0.062 \\
(0.039)\end{array}$ \\
\hline $\ln A I D S L_{6}$ & $\begin{array}{l}0.030 * * * \\
(0.006)\end{array}$ & $\begin{array}{l}0.014 \\
(0.017)\end{array}$ & $\begin{array}{l}0.051 * * * \\
(0.010)\end{array}$ \\
\hline lnsed & $\begin{array}{l}-0.019 \\
(0.026)\end{array}$ & $\begin{array}{l}0.052 \\
(0.064)\end{array}$ & $\begin{array}{l}-0.005 \\
(0.017)\end{array}$ \\
\hline $\operatorname{lnpln}$ & $\begin{array}{l}0.033 \\
(0.028)\end{array}$ & $\begin{array}{l}-0.032 \\
(0.080)\end{array}$ & $\begin{array}{l}0.683 \\
(0.518)\end{array}$ \\
\hline $\operatorname{lng} s$ & $\begin{array}{l}-0.022 * * * \\
(0.005)\end{array}$ & $\begin{array}{l}-0.024 * * * \\
(0.005)\end{array}$ & $\begin{array}{l}0.141 \\
(0.105)\end{array}$ \\
\hline $\operatorname{lng} c f$ & $\begin{array}{l}0.052 * * * \\
(0.008)\end{array}$ & $\begin{array}{l}0.061 * * * \\
(0.014)\end{array}$ & $\begin{array}{l}-0.016 \\
(0.036)\end{array}$ \\
\hline lnopn & $\begin{array}{l}0.015 \\
(0.022)\end{array}$ & $\begin{array}{l}-0.008 \\
(0.030)\end{array}$ & $\begin{array}{l}0.199 * * \\
(0.080)\end{array}$ \\
\hline Observations & 252 & 144 & 108 \\
\hline Countries & 42 & 24 & 18 \\
\hline Instruments & 30 & 20 & 20 \\
\hline Sargan test (p-value) & 0.246 & 0.541 & 0.468 \\
\hline AR (2) test (p-value) & 0.629 & 0.896 & 0.414 \\
\hline
\end{tabular}

Note: Dependent variable $\left(\operatorname{lng} d p_{i t-1}\right)$ : GDP per capita growth; lnhiv: HIV prevalence rate; $\ln A I D S L_{6}$ : AIDS; lnsed: secondary education general pupil; $\operatorname{lnp} \ln$ : total population; $\operatorname{lng} c f$ : capital formation; lngs: domestic savings; lnopn: openness; standard errors in parentheses; $* * *, * *$ and $*$ denotes significance at the 1,5 and 10\% levels, respectively; all time dummies are allowed for but not reported to save space.

\section{Conclusion}

This paper empirically examines the effect of HIV/AIDS on economic growth. The results suggest that current HIV prevalence rate, associated with high level of illnesses and absenteeism impact negatively on GDP per capita and, in so doing affect economic performance in the sub-Saharan Africa. Conversely, AIDS; associated with high mortality in addition to morbidity has positive effect on per capita GDP. The positive effect was due to declining population as a result of an increase in mortality; AIDS related and otherwise, rather than growth augmenting policies or activities. Thus, while on the one hand, the finding confirmed the hypothesis that HIV epidemic reduces the growth rate of GDP per capita in 
sub-Saharan Africa, and by extension economic growth, on the other hand, it suggests that high AIDS prevalence increases per capita GDP, which could only come at the expense of declining national populations. The sub-sample sensitivity analyses, reflect the existence of these essential differences in the association of the HIV/AIDS epidemic and economic growth in the sub-Saharan Africa region. Consequently, the results offer useful and additional information which indicates that the macroeconomic effects of the HIV/AIDS epidemic are substantial. Essentially, even in the countries of the Eastern and Southern Africa sample, where a positive effect was shown, in the long-run, as more productive and experienced labour succumbed to AIDS, productivity could be so low that in the face of increased death, AIDS will in essence begin to have a negative effect on GDP per capita. Thus, on the policy aspect, it is imperative for various governments in the sub-Saharan Africa region to take appropriate measures to curb the scourge of the widely spread HIV/AIDS epidemic in the region.

\section{References}

Ainsworth, M., \& Over, M. (1994). AIDS and African development. World Bank Research Observer, $9(2), 203-240$.

Ali, A., \& Imai, K. S. (2015). Crises, economic integration and growth collapse in African countries. Journal of African Economies, 24(4), 471-501. http://dx.doi.org/10.1093/jae/ejv010

Arellano, M., \& Bond, S. (1991). Some tests of specification for panel data: Monte Carlo evidence and an application to employment equations. Review of Economic Studies, $58(2), 277-297$.

Arellano, M., \& Bover, O. (1995). Another look at the instrumental-variable estimation of error components models. Journal of Econometrics, 68(1), 29-52.

Arndt, C., \& Lewis, J. D. (2000). The macro implications of HIV/AIDS in South Africa: A preliminary assessment. South African Journal of Economics, 68(5), 380-392.

Asiedu, E., Jin, Y., \& Kanyama, I. (2011). The impact of HIV/AIDS on foreign direct investment in developing countries. University of Kansas Mime.

Baltagi, B. H. (2005). Econometric analysis of panel data ( $3^{\text {rd }}$ ed.). England: John Wiley \& Sons Ltd.

Barro, R. J., Sala-i-Martin, X., Blanchard, O. J., \& Hall, R. E. (1991). Convergence across states and regions. Brookings papers on economic activity, 107-182.

Bloom, D. E., \& Mahal, A. S. (1997). Does the AIDS epidemic threaten economic growth? Journal of Econometrics, 77(1), 105-124.

Blundell, R., \& Bond, S. (1998). Initial conditions and moment restrictions in dynamic panel data models. Journal of Econometrics, 87(1), 115-143. 
Bonnel, R. (2000). HIV/AIDS and economic growth: A global perspective. South African Journal of Economics, 68(5), 360-379.

Bos, E., \& Bulatao, R. A. (1992). The demographic impact of AIDS in sub-Saharan Africa: Short-and long-term projections. International Journal of Forecasting, 8(3), 367-384.

Cuddington, J. T. (1993). Modelling the macroeconomic effects of AIDS, with an application to Tanzania. The World Bank Economic Review, 7(2), 173-189.

Cuddington, J. T., \& Hancock, J. D. (1994). Assessing the impact of AIDS on the growth path of the Malawian economy. Journal of Development Economics, 43(2), 363-368.

Dixon, S., McDonald, S., \& Roberts, J. (2001). AIDS and economic growth in Africa: A panel data analysis. Journal of International Development, 13(4), 411-426. doi: 10.1002/jid.795

Dixon, S., McDonald, S., \& Roberts, J. (2002). The impact of HIV and AIDS on Africa's economic development. British Medical Journal, 324(7331), 232-234.

Forgel, R. W. (1994). Economic growth, population theory, and physiology: The bearing of long-term processes on the making of economic policy. American Economic Review, 84(3), 369-395.

Haacker, M. (2011). Framing AIDS as an economic development challenge. Brown Journal of World Affairs, 17(11), 65-76.

Joint United Nations Programme on HIV/AIDS and World Health Organisation. (2001). AIDS Epidemic Update 2001. UNAIDS, Geneva. Retrieved from http://www.unaids.org

Joint United Nations Programme on HIV/AIDS and World Health Organisation. (2010). UNAIDS Report on the Global AIDS Epidemic 2010. UNAIDS, Geneva, Retrieved from http://www.unaids.org

Joint United Nations Programme on HIV/AIDS and World Health Organisation. (2009). AIDS Epidemic Update 2009. UNAIDS, Geneva. Retrieved from http://www.unaids.org

Joint United Nations Programme on HIV/AIDS. (2005) Global Report: UNAIDS Report on the Global AIDS Epidemic 2005, Geneva, Switzerland. Retrieved from http://www.unaids.org

Joint United Nations Programme on HIV/AIDS. (2007) Global Report: UNAIDS Report on the Global AIDS Epidemic 2007, Geneva, Switzerland. Retrieved from http://www.unaids.org.

Joint United Nations Programme on HIV/AIDS. (2008) Global Report: UNAIDS Report on the Global AIDS Epidemic 2008, Geneva, Switzerland. Retrieved from http://www.unaids.org. 
Joint United Nations Programme on HIV/AIDS. (2012) Global Report: UNAIDS Report on the Global AIDS Epidemic 2012, Geneva, Switzerland. Retrieved from http://www.unaids.org.

Joint United Nations Programme on HIV/AIDS. (2013) Global Report: UNAIDS Report on the Global AIDS Epidemic 2013, Geneva, Switzerland. Retrieved from http://www.unaids.org.

Joint United Nations Programme on HIV/AIDS. (2014) Global Report: UNAIDS Report on the Global AIDS Epidemic 2014, Geneva, Switzerland. Retrieved from http://www.unaids.org.

Kambou, G., Devarajan, S., \& Over, M. (1992). The economic impact of AIDS in African country: Simulation with a computable general equilibrium model of Cameroon. Journal of African Economies, 1(1), 109-130.

Kanki, P. J., Hamel, D. J., Sankalé, J. L., Hsieh, C. C., Thior, I., Barin, F., ... \& MBoup, S. (1999). Human immunodeficiency virus type 1 subtypes differ in disease progression. Journal of Infectious Diseases, 179(1), 68-73.

Kendrick, J. W. (1976). The formation and stocks of total capital. New York: Columbia University for NBER.

Knowles, S. P., \& Owen, D. (1995). Health capital and cross country variation in income per capita in the Mankiw-Romer-Weil model. Economic Letters, 48, 96-106.

Levine, R., \& Zervos, S. (1998). Stock markets, banks, and economic growth. American Economic Review, 88, 537-558.

Lovasz, E., \& Schipp, B. (2009). Impact of HIV/AIDS on economic growth in sub-Saharan Africa. South African Journal of Economics, 77(2), 245-256

Mankiw, N. G., Romer, D., \& Weil, D. N. (1992). A contribution to the empirics of economic growth. The Quarterly Journal of Economics, 107, 407-437

Mayer, D. (2001). The long-term impact of health on economic growth in Latin America. World Development, 29(6), 1025-1033.

McDonald, S., \& Robbers, J. (2006). AIDS and economic growth: A human capital approach. $\begin{array}{llll}\text { Journal of Development } & \text { Economics, } & \text { 80(1), }\end{array}$ http://dx.doi.org/10.1016/j.jdeveco.2005.01.004

Murray, C. J., \& Lopez, A. D. (1996). Evidence-Based Health Policy-Lessons from the Global Burden of Disease Study. Science, 274(5288), 740-743.

Murtin, F., \& Marzo, F. (2013). HIV/AIDS and poverty in South Africa: A Bayesian estimation of selection models with correlated fixed effects. South African Journal of Economics, 81(1), 118-139. 
Roodman, D. (2009). A note on the theme of too many instruments. Oxford Bulletin of Economics and statistics, $71(1)$ 135-158. http://dx.doi.org/10.1111/j.1468-0084.2008.00542.x

Todaro, M. P., \& Smith, S. C. (2005). Economic development $\left(8^{\text {th }}\right.$ ed.). Singapore: Pearson educational publisher's ltd.

World Bank (2011). The World Bank annual report 2011. Washington DC, USA http://documents.worldbank.org/curated/en/2011

World Bank. (2000). The development impact of HIV/AIDS: Selected issues and options, Lesotho. World Bank Macroeconomic Technical Group, Report No. 21103.

World Bank. (2001). Selected development impact of HIV/AIDS: Swaziland. World Bank Macroeconomic Technical Group, Report No. 22044.

World Bank. (2014). World Development Indicators. World Bank, Washington. Retrieved from http://www.worldbank.org/research/growth

World Health Organization. (1995). The current global situation of the HIV/AIDS epidemic. Global Programme on AIDS, Geneva.

World Health Organization. (2008). The current global situation of the HIV/AIDS epidemic. Global Programme on AIDS, Geneva.

Young, A. (2005). The gift of the dying: The tragedy of AIDS and the welfare of future African generations. The Quarterly Journal of Economics, 120(2), 423-466

\section{Notes}

Note 1. The data for GDP per capita growth are negative for some of the observations. To enable taking their log, adding the highest negative value plus one across all the observations ensures that all are positive. These change only the intercept, while importantly, the slope remains unchanged, Asiedu, Jin and Kanyama (2011) and Ali and Imai (2015). 2The HIV prevalence rate being cumulative, it is believed after six years, HIV will develop to AIDS. Therefore, AIDS is measured using six years lags of the HIV prevalence rate.

Note 2. The data for gross domestic saving as a percentage of GDP and 4population growth are negative for some of the observations. To enable taking their log, adding the highest negative value plus one across all the observations ensures that all are positive. These change only the intercept, while importantly, the slope remains unchanged, Asiedu, Jin and Kanyama (2011) and Ali and Imai (2015). 


\section{Macrothink}

Appendix I: List of countries in the sample

\begin{tabular}{ll}
\hline Eastern and Southern Africa & Rest of Sub-Saharan Africa \\
\hline Botswana & Angola \\
Burundi & Benin \\
Ethiopia & Burkina Faso \\
Kenya & Cape Verde \\
Lesotho & Cameroon \\
Madagascar & Central African R. \\
Malawi & Chad \\
Mauritius & Congo, Dem. R. \\
Mozambique & Congo \\
Namibia & Cote d'Ivoire \\
Rwanda & Equatorial Guinea \\
South Africa & Gabon \\
Sudan & Gambia \\
Swaziland & Ghana \\
Tanzania & Guinea \\
Uganda & Guinea-Bissau \\
Zambia & Liberia \\
Zimbabwe & Mali \\
& Mauritania \\
& Niger \\
& Nigeria \\
& Senegal \\
& Sierra Leone \\
\hline
\end{tabular}

\section{Copyright Disclaimer}

Copyright for this article is retained by the author(s), with first publication rights granted to the journal.

This is an open-access article distributed under the terms and conditions of the Creative Commons Attribution license (http://creativecommons.org/licenses/by/3.0/). 